\title{
Independent Living for Persons with Disabilities
}

\section{Mary Runo}

\section{(2) OpenEdition}

\section{Journals}

Electronic version

URL: https://journals.openedition.org/eastafrica/432

DOI: 10.4000 /eastafrica.432

ISSN: 2790-1076

\section{Publisher}

IFRA - Institut Français de Recherche en Afrique

\section{Printed version}

Date of publication: 1 October 2012

Number of pages: 11-25

ISSN: 2071-7245

\section{Electronic reference}

Mary Runo, "Independent Living for Persons with Disabilities", Les Cahiers d'Afrique de l'Est / The East African Review [Online], 46-1 | 2012, Online since 07 May 2019, connection on 10 December 2021. URL: http://journals.openedition.org/eastafrica/432 ; DOI: https://doi.org/10.4000/eastafrica.432

This text was automatically generated on 10 December 2021.

Les Cahiers d'Afrique de l'Est / The East African Review 


\title{
Independent Living for Persons with Disabilities
}

\author{
Mary Runo
}

\section{Introduction}

1 Kenya, like any other developing country, is faced with pertinent issues on disabilities which have not been fully addressed at school and national levels. One such issue is the preparedness of all sectors working with or for People with Disabilities (PwDs) in terms of Independent Living (IL). The four traditional areas of disabilities in Kenya, namely physical disabilities, hearing impairment, visual impairment and mental disabilities (mental retardation), have been the main focus for several decades. Yet, today a majority of these PwDs do not have adequate training and services to enable them live independently. Of the four traditional areas, I take exception of persons with mental disabilities (intellectual disabilities) who remain in school for many years without acquiring independent living skills. Some educational and rehabilitation centres have mature adults aged 30 years and above who cannot support themselves in the community because they never trained in any useful transitional skills.

2 The other three categories (i.e visual impairments, hearing impairment and physical disabilities) also do not seem to do much better after education or training. Only a handful proceeds beyond primary education and even fewer attain post-secondary training due to poor preparation for independent living. Consequently, some of them go to the streets to beg, others settle for semi-skilled jobs such as selling sweats and other small items or end up being cobblers or even simple carpentry skills. A few others stay home with their families depending on parents or guardians for basic needs. The question therefore arises: "After school, what?"

3 In developed countries, persons with moderate and severe mental disabilities are trained in IL skills, whether at community level or in rehabilitation centres, and many are able to live independently or semi-independently with support. Those with mild mental disabilities join high schools while those who are severe are not economically 
viable even with supervision. In Kenya, the majority of those with mild intellectual disabilities is dependent and hardly gets beyond class six. Those with autism especially the severe cases are dependents all their lives. Some parents/guardians of such children live with a mixture of hope and fear of what will become of their children. Others give up hope on their children and wait for fate. Occasionally, we see adults chaired or locked in the house. The questions can be asked: "Can all persons with disabilities acquire Independent Living skills? Do they have equal rights to share the national cake with those without disabilities? For how long will PwDs be viewed "unable" and "charitable?" These questions can only be answered if we underscore what is exactly "Independent Living" for the PwDs.

\title{
What is Independent Living for PwDs?
}

\begin{abstract}
"Independent Living is a philosophy and a movement of people with disabilities who work for self-determination, equal opportunities and self-respect. Independent Living does not mean that PwDs want to do everything by themselves and that they do not need anybody or that they want to live in isolation. PwDs demand the same choices and control in their every-day lives that people without disabilities take for granted. PwDs want to grow up with their families, go to the neighborhood school, use the same bus as their neighbours, and work in jobs that are in line with their education and interests, and start families of their own" (Ratzka, 2005).
\end{abstract}

\section{Possible prevalence of PwDs in Kenya}

4 According to the World Health Organization (WHO, 2011), there are 7 billion people in the world among them $15 \%$ of people with disabilities, which is equivalent to about 1 billion people. If we use WHO statistics of $10-15 \%$ people with disabilities, Kenya could have between 4 to 6 million PwDs, whether children, youth and adults. Yet, less than half a million has been identified and is catered for. However, according to a preliminary report by the Kenya National Survey for Persons with Disabilities (2008), PwDs are only $4.6 \%$ with a majority residing in the rural areas and a handful in urban areas. The report also focused on the same traditional four areas above-mentioned. Other types of disabilities included in the report were not specified. From the above report, the fact that Kenya does not know the exact number of PwDs limits the reach and scope of social programs required to empower PwDs with IL skills, leave alone measures required for prevention and full treatment. Moreover, other types of disabilities than the four commonly addressed ones have always been ignored and not given the attention they deserve.

5 According to this survey, about $80 \%$ of the world's PwDs live in low-income countries where they experience social and economic disadvantages and problems of access to their rights. The lives of PwDs are made more difficult by the way society interprets and reacts to disabilities. Furthermore, disability is known to be a cause of poverty and a result of poverty, while, additional conditions that complicate the lives of PwDs are made of social and physical environmental barriers. This explains why PwDs are dependent rather than independent, and segregated rather than included in the society. 


\section{National policies on disabilities}

6 Kenya has a few national policies that support PwDs and is also a signatory to international policies. One such policy which is in force is the National Special Needs Education Policy Framework (2009). In this policy, the Government of Kenya (GoK) through the Ministry of Education recognizes 22 types of special needs divided into people with disabilities and people with special needs like orphans and children living in the streets. As it appears, the government of Kenya is committed to the protection and provision of equal opportunities to persons with special needs and disabilities since 1964. Since then, education and care for PwDs has gradually improved and the landmark of all the policies is the National Special Needs Education Policy Framework (2009).

7 This 2009 policy framework recognizes the mandate of the Government of Kenya to be in line with global goal of providing universal primary education. Providing education as a right is an obligation of all governments and requires that they translate their national commitments into legislation. The GoK through its policy on Free Primary Education (2003) recognized that Special Needs Education activities and services were poorly coordinated and many learners were not accessing education. The Session paper No. 1 of 2005 emphasizes the need to develop a comprehensive Special Need Education (SNE) policy that covers all aspects and levels of education. While this policy is highly appreciated as a big landmark to the plight of PWDs, it does not specifically provide a clear objective on the provision of independent living skills in all its eleven (11) objectives. Youth and adults or PWDs above 14 years old are expected to fit within the said objectives especially identification, rehabilitation, educational needs, inclusion of formal and non-formal training, and promotion of barrier force environment and so forth. Out of the 11 objectives the youth and adults with disabilities who are not catered when it comes to empowering them for independent living are targeted. However, the stakeholders and the communities are not directly included as actors to plan for independent living skills and activities either.

\section{The Persons with Disabilities Act, 2003}

Another landmark policy initiated by the government is the Disabilities Act 2003. It is an Act of Parliament that provides for the rights and rehabilitation of persons with disabilities. It focuses on empowering persons with disabilities and equalization of opportunities by ensuring to the maximum extent possible that PwDs obtain education and employment and participate fully in sporting, recreational and cultural activities.

9 In summary the PwDs should access all provisions and opportunities such as education, health, employment, rehabilitation, civil rights, incentives and funding first like persons with disabilities in the country. The 2003 Act is a step forward in the plight of PwDs but, again, it requires a much deeper thought on how to empower and make provision what rightly belongs to PwDs. The National Council for Persons with Disabilities established through this Act has been mandated to oversee the its implementation, and develop measures and policies that would be beneficial to PwDs. While the mandate of the Council appears quite comprehensive, there is need to spell 
out precisely in "black and white" how to empower PwDs with IL skills, what is required in terms of human and material resources.

\section{Special needs in Kenya}

10 Education and care for PwDs in Kenya started right after the Second World War around 1946 with the establishment of the first school for the blind. Soon after 1948 a school for learners with mental handicaps was established, which included learners with hearing impairments in 1958 and finally, those with physical disabilities 1962. These four categories of impaired people have for many decades been referred to as the traditional "four" in Kenya because they were the only ones who were addressed in teachers' training, curriculum development and programs in schools and rehabilitation centres. To date, advocates and professionals of other categories of disabilities have risen up to fight for their recognition by both the government and society. This paper will present a few of these other categories of disabilities. They include: autism, emotional and behavioural disorders, learning disabilities (including dyslexia), speech and language disorders, deafblind and multiple disabilities. Other recognized special needs in Kenya are cerebral palsy, epilepsy, the Down syndrome, albinism and finally the gifted and the talented. While this paper focuses on IL for PwDs, different types of disabilities will be described for full coverage of the issue.

\section{Relevance of Millennium Development Goals (MDGs), Vision 2030 and Constitution to disabilities}

11 The MDGs are specially designed to address the needs of the world's poorest citizens and most marginalized population in order to achieve the goals of the United Nations and its commitment to promote the rights and development for all. It has been noted that there is a reciprocal relationship between disability and poverty. As a result, many poor families have children with disabilities. In most cases a child with disabilities will cost the parents/guardians and governments ten times more than children without disabilities in terms of assessments, special services health, upkeep, education and assistive devices or equipment. It is common knowledge then that MDGs cannot be attained in 2015 without giving priorities to the plight of PwDs. Without concerted effort by the government and all the stakeholders, PwDs will still remain marginalized.

Kenya's Vision 2030, which is basically 16 years from today, will remain unachieved if the plight and rights of PwDs are not addressed. The PwDs and their families, especially the poor, will continue begging for their most basic rights i.e. education, shelter, health, food and security in the coming years.

The Constitution of Kenya (2010, Clause 54) requires a big thought for its full interpretation and inclusion in order for the proposed laws to be useful to PwDs. It is at this point that all the stakeholders should be included to make this clause serve all those with disabilities beyond the "traditional four". According to Lerner (2006), out of $100 \%$ of all PWDs, $50 \%$ have learning disabilities, $20 \%$ have language and speech impairments, $10 \%$ have mental retardation, $8 \%$ have emotional and behavioural disorders - all other disabilities, that is, physical disabilities, health impairments, physical disabilities, hearing impairments, visual impairments and autism making up 
the remaining 12\%. In short, for Kenya to be in line with the MDGs, realize Vision 2030 and implement the 2010 Constitution, all types of PwDs must be fully identified and targeted so as to enjoy the dignity and respect they deserve.

\section{Short description of types of disabilities}

1. Learning Disability-Obstacles to the learning process that hinder a person's full ability to be educated. A disorder in one or more of the basic psychological processes involved in understanding or in using language, spoken or written which may manifest itself in an imperfect ability to listen, think, speak, read, write, spell or to do mathematical calculations. Dyslexia is a specific learning disability that is neurological in origin. It is characterized by difficulties with accurate and/or fluent word recognition and by poor spelling and decoding abilities. These difficulties typically result from a deficit in the phonological component of language that is unexpected in relation to other cognitive abilities and the provision of effective classroom instructions.

15 2. Emotional and Behaviour Disorders-Refers to a condition in which behavioral or emotional responses of an individual are so different from his/her generally accepted, age-appropriate, ethnic, or cultural norms such that they affect performance in such areas as self-care, social relationships, personal adjustment, academic progress, classroom behavior, or work adjustment. Emotional behaviour disorders must be exhibited in at least two different settings.

3. Hearing Impairments-Impairment in hearing, whether permanent or fluctuating, that adversely affects one's educational performance.

4. Visual Impairments-Impairment in vision that, even with correction, adversely affects one's educational performance. The term includes both partial sight and blindness.

18 5. Physical Disabilities-The term includes impairments caused by congenital anomaly (e.g. club foot, absence of limbs, etc.), impairments cause by disease (e.g., poliomyelitis, bone tuberculosis, etc.), and impairments from other causes (e.g., cerebral palsy, amputations and fractures or burns etc.).

6. Other Health Impairments-Other health impairments is a generic term used to refer to several physical conditions or diseases that have an impact on the individual's functioning. Descriptions of several of the conditions follow. Learners with these health impairments are disabled only to the extent that the health condition restricts their participation at home, in the school and in the community.

\section{Speech and Language Impairments}

- Speech Impairment-Impairment of speech articulation, voice, fluency or the impairment language comprehension and oral expression or the impairment of the use of a spoken, or other systems.

- Language impairment-impairment in the ability to understand and/or use words in context, both verbally and non-verbally. Some characteristics of language impairment include improper use of words and their meanings, inability to express ideas, inappropriate grammatical patterns, reduced vocabulary and inability to follow directions. 
8. Mental Retardation-A disability characterized by significant limitations both in intellectual functioning and in adaptive behavior as expressed in conceptual, social and practical adaptive skills. This disability originates before the age of 18 .

9. Autism-A complex developmental disability that typically appears during the first three years of life. It is caused by a neurological disorder that affects the functioning of the brain, impacting development in the areas of social interaction and communication skills. Both children and adults with autism show difficulties in verbal and non-verbal communication, social interactions, and leisure or play activities.

10 Down Syndrome (DS)-To the most common cause of mental retardation and malformation in a newborn. It occurs because of the presence of an extra chromosome.

11. Deaf-Blind-Refers to sensory impairment, visual impairment and hearing impairment occurring in combination with each other. Frequently, other disabilities also occur with the combination of a visual and hearing impairment. The combination of these disabilities causes significant challenges to accommodation. Tactile solutions are often appropriate.

12. Albinism-An inherited condition repent at birth, characterized by a lack of pigment that normally gives colour to the skin, hair and eyes.

13. Multiple disabilities-Children with multiple disabilities have two or more disabling conditions that affect learning or other important life functions. These are concomitant impairments such as mental retardation-blindness, mental retardationorthopedic impairment, etc. Such combinations cause such severe educational need that children cannot be accommodated in special education programs developed solely for one of the impairments. The term does not include deaf-blind.

14. Epilepsy-Any of a group of syndromes characterized by paroxysmal transient disturbances of the brain function that may be manifested as a episodic impairment or loss of consciousness, abnormal motor phenomena, psychic or sensory disturbances, or perturbation of the autonomic nervous systems; symptoms are due to disturbance of the electrical activity of the brain.

\section{The strong voice of PwDs}

People with disabilities can no longer be ignored both globally and nationally. In Kenya the traditional four have kept the fight going for decades for recognition and human rights. Those who have visual impairments, physical disabilities and hearing impairment have developed self-advocacy thus making great strides in the country. People with mental disabilities have been advocated for by their families and professionals. Today, we have many other types of disabilities who are either selfadvocates or are being advocated for. At the end of it all it is important to speak the same language in order to be fully involved in all aspects of life just like any other citizen in Kenya. Concerning IL skills, the PwDs say:

"Since we are the best experts on our needs, we need to show the solutions we want, need to be in charge of our lives, think and speak for ourselves-just as everybody else. We must support and learn from each other, organize ourselves and work for changes that lead to the legal protection of our human and civil rights" (Ratzka, 2005).

In some societies or communities, especially in Africa, people have preconceived ideas and issues that contribute to negative attitudes towards PwDs, portraying them as 
unable, sick, deviant or even bad omen. In some cases parents blame each other or are completely isolated because of having a child with disabilities. However, when youth with disabilities and their families are well supported and empowered, such youth can and do live independently or semi-independently. For the PwDs to acquire IL there are certain emerging issues to contend with. Some of such issues include the modification, adaptation of the regular curriculum as well as specialized curriculum. It also entails time given to various essential services to enable PwDs to acquire the necessary skills for IL. Moreover, there is need for a change of attitude towards people without disabilities, including respecting the rights of PwDs. The existing educational and rehabilitation programs should also be well equipped to train transition skills and a well-trained personnel both professional and support staff and well utilized. The government should also ensure that enough material and finances are allocated for PwDs and, finally, the society should be sensitized on issues of disabilities by use of the Kenyan Constitution and the National Disability Act among others.

Generally PwDs will require assistance and empowerment on the following areas among others.

- Social skills, e.g sharing and relating with others

- Health, safety and problem solving

- Employment skills

- Transportation

- Functional skills including use of money

- Stress management skills

- Family life

\section{Introducing IL skills at an early age}

Independent Living (IL) skills are a collection of age appropriate skills necessary for leading the most self-sufficient life possible. The scope of these skills will change and grow as the person ages and learns new sets of skills. Teaching the importance of being responsible for oneself will reap benefits for a lifetime. When children learn that one can be able and capable of a variety of tasks and activities, their self-esteem is enhanced:

"The process of learning to be accountable for independent behaviors while functioning as part of a family, team, group or community is a delicate balance that must begin at an early age and continue through adulthood. It's never too early to start working on independent living skills. For most kids the earlier they learn to contribute to their surroundings, the more it becomes an integral part of their routine. At about age two, each child should begin assuming responsibilities appropriate to their performance level" (Quinn, 2011).

Children with disabilities (whether the disability is a result of mental, physical, sensory, or behavior or communication characteristics) will require training of IL early enough even though they are limited in many ways. For example, Inhelder (1968) quoted in Beirne-Smith et al (1998) viewed the cognitive development of children with mental retardation and concluded that these children will develop in the same way as those without disabilities but at a slow pace depending on the severity of their disability. This means that if all educators, parents and significant others were well equipped, they would train children with mental retardation on IL early enough, and therefore would 
not have to wait until the child is grown and waste a lot of valuable time. Likewise, all children with disabilities should be trained early enough.

Quinn (2011) elaborates the skills to be given to children, youth and adults, which includes household maintenance, use of time and money, social skills and simple meal preparation. At secondary school level she asserts that youth and young adults should be having a repertoire of skills such as home management skills, daily living skills, community involvement, interpersonal relationship skills, job development and retention skills. Finally she says:

"Working hard to prepare our young people for the adult world is a huge responsibility. Through it all, let's not forget what each and every one of us really wants for these young adults: to live the most productive life possible, to feel fulfilled and satisfied with that life and most importantly, to be HAPPY!" (Quinn, 2011).

\section{Preparing PwDs for Independent Living}

There is a dire need to develop curricula that will have a component of IL skills and activities necessary for transition from school to the world of work and within the community. The Development and Transition (DCDT) programme of the Council for Exceptional Children (quoted in Beirne-Smith et al, 1998) refers to transition as:

“... a change in status from behaving primarily as a student to assuming emergent adult roles in the community. These roles include employment, participating in post-secondary education, maintaining a home, becoming appropriately involved in the community, and experiencing satisfactory person and social relations. The process of enhancing transition involves the participation and coordination of school programs, adult agency services, and natural supports within the community. The foundations for transition should be laid during the elementary and middle school years, guided by the broad concept of career development. Transition planning should begin no later than age 14, and students should be encouraged, to the full extent of their capabilities, to assume a minimum amount of responsibility for such planning' (Ibid.: 352).

Beirne-Smith et al (Ibid.) gave the following points to be considered for IL training. First, he noted that, individuals must be prepared for a number of different adult roles-of which employment is only one. Second, cooperation and communication are essential for this process to work. Third, transition efforts (instruction and planning) need to begin at an early age. The precursors of transition planning and services should start at the primary level. The planning piece must begin many years before the student exits the school system. And fourth, a major effort should be made to empower students to become key players in the transition planning process.

Beirne-Smith et al (Ibid.) further asserts that the transition planning process is, at its core, a shared responsibility of the school, home, the student and adult service providers. The process, if implemented appropriately, should lead to the acquisition of important knowledge, skills and connections with essential supports and services in the community. These will finally contribute to assisting the individual to deal with the challenges and the demands of everyday life. Ultimately, if this outcome is achieved, the individual is likely to experience some sense of personal fulfilment.

37 According to Taylor (2000) transition planning and programming should begin around $14^{\text {th }}$ year of life when the student is joining high school. In Kenya, the student may be still in primary school depending of the time he/she joined school and also the type and severity of the disability. Some learners with mild mental disabilities and those 
with learning disabilities may still be in primary school having been repeated severally due to poor identification process.

Before any transition program is planned there is a need to have the learners fully assessed in various areas such as:

- Interest inventories-what is the learner's interest and ability.

-Work samples-what is the individual capable of doing without causing any stress and what he/she can do independently or with support or supervision.

- On-the-job assessment-having a person to attend a few sessions and fully participate in the job such as working in a factory, supermarket or school, where he works under a supervisor for 3-4 hours a week as he attends vocational classes.

- Other assessments will include, time assigned and utilized on a task, grooming and communication with adults and co-workers in a factory, office, school, supermarket and so on.

- Vocational assessment is critical to the transition process and independent living as the student prepares to leave primary school and joining the community while continuing with schooling/training. A lot of our school leavers with disabilities remain dependents for life because of lack of assessment and lack of proper preparation. In other words, our educational programmes have not infused and incorporated transitional programs in the curriculum.

Some learners with disabilities are almost "ignored" because of the disability they have and yet through assessment and proper training they can either live semiindependently with supervision or independently with very little supervision. There is a big gap between the training for independent living in our schools and rehabilitation centres.

\section{Functional Living Skills Instruction}

Appropriate education for students with disabilities must be implemented according to individual needs and to the functional skills demands of adulthood. Functional skills are those an adult needs to perform successfully in a variety of community settings. Clark (1991) quoted in Mercer \& Mercer (2001) defines functional curriculum as instructional content that focuses on the concepts and skills needed by students in the areas of personal social, daily living, and occupational adjustment.

41 Functional living skills must be taught directly and systematically to some students with learning problems, or otherwise the students may never acquire these essential skills or may learn them through trial and errors, which is both costly and timeconsuming. Brolin (1993) quoted in Mercer \& Mercer (2001) provides the following competencies and competencies in daily living skills:

- Managing personal finance: making responsible expenditure e.g counting money and making correct change; keeping basic financial records; calculating and paying taxes; using credit responsibly; and using banking services.

- Selecting and managing a household: For example, maintaining home environment; using basic appliances and tools; selecting adequate housing; setting up household; and maintaining home grounds. 
- Caring for personal needs: Demonstrating knowledge of physical fitness, nutrition, and weight; exhibiting proper grooming and hygiene; dressing appropriately; demonstrating knowledge of common illness prevention and treatment; practicing personal safety.

- Buying, preparing, and consuming food: For example, purchasing food; clearing food preparation areas; storing food; prepares meals; demonstrating appropriate eating habits; planing for balanced meals.

- Appropriate use of clothing: Washing and cleaning clothing; purchasing clothing; ironing, mending, and storing clothing.

- Exhibiting responsible citizenship: Demonstrating knowledge of civic rights and responsibilities; knowing nature of local, state, and federal governments; demonstrating knowledge of the law and ability to follow the law; demonstrating knowledge of citizen rights and responsibilities.

- Engaging in use of recreational facilities: Demonstrating knowledge of available community resources; choosing and planning activities; demonstrating knowledge of the value of creation; engaging in collective and individual activities; planing vocation time.

- Involving in the community affairs: For example, demonstrating knowledge of traffic rules and safety; demonstrating knowledge and use of various means of transportation; finding way around the community; driving a car.

\section{Effective transition program for PwDs}

For a transition program to be effective for PwDs' independent living, the following is required:

- Individualized planning

- Systematic vocational assessment, job exploration, vocational counselling, and vocational skills training

- Academic remediation where necessary as determined by the disability and the individual

- Advocacy training on social skills and social support - The identification and coordination of support systems such as vocational rehabilitation

- Coordination and collaboration with employers

- A systematic job-seeking curriculum featuring job search skills

- An evaluation plan to monitor both short-term and long-term effectiveness of the program

\section{Transition program participants}

Participants in the program include individuals who play different roles:

- Special educators: They teach job-related academic strategies, social skills, and job-finding and job-seeking program prerequisites; collaborate with the transition team to coordinate the plan; teach self-advocacy.

- Guidance counselors: They provide individual and small group counselling; provide career awareness and exploration information.

- Vocational evaluators or school psychologists: They conduct vocational relevant evaluations.

- Employers: They provide information about job needs and requirements; provide job training sites and permanent jobs; evaluate students before and after graduation, allow attachments.

- Vocational educators: They provide vocational training both in and out of school, and PwDs for job placement; also make instructional modification when appropriate; obtain information regarding job needs and job requirements. 
- Parents: They need to help adolescents develop realistic career goals; promote and support independence; help adolescents explore career options and where necessary collaborate with employers for practicums or attachments.

- Students: They acquire skills needed to be vocationally successful; work toward achieving independence; acquire strategies and skills needed.

- Vocational rehabilitation counselors: They obtain funding for job-related services; provide vocational evaluation information; assist with job placement and provide support services; act as primary postsecondary receiving agency. Advice where and how to start rehabilitation centres and sheltered workshops.

\section{The Individualized Education Programme (IEP)} for an individual learner is appropriate for that learner's special learning needs and that the special education services are actually delivered and monitored. The IEP is an accountability document that outlines the learner's expectations, assessment strategies, and performance standards. Therefore, teachers and other school personnel must prepare such an IEP for every student receiving special education services. A good IEP includes the following components:

- Present level of performance. The IEP must state the child's present levels of educational performance or functioning. The information usually comes from the assessment results such as classroom tests and assignments, individual tests given to decide the level of functioning. Observations by parents, teachers and related service providers are equally important. This component also includes how the child's disability affects his or her involvement and progress in general education.

- Annual goals. These are goals that are projected by the teacher or assessor. Goals may be academic or non-academic such as those addressing social or behavioural needs, physical needs, or other educational needs. These goals must be measurable and attainable.

- Special education and related services. The IEP must list the special education and related services to be provided to the child or on behalf of the child. This includes supplementary aids and services that the child requires including the weekly or monthly clinics the child attends.

- Project dates. A projection concerning the initiation of services as well as the anticipated dates of the service completion.

- Evaluation. An evaluation procedure and its timeline, and the people participating in the IEP. 


\section{The role of community in empowering PwDs for Independent Living} institutions. To move away from institutional care to community living, communitybased services are required to support PwDs live independently in the community. This is in line with the philosophy of inclusion and mainstreaming disabilities where zero (0) reject, respect and rights are paramount. Community living has been defined as comprising the same range of accommodation available for the population in the same locations where the general population resides, offering PwDs choice over where and with whom they live and providing the necessary support for community participation.

Finally, in order to live independently in a community PwDs require empowerment and training on various areas such as ability to make choice and participate in all aspects of life and in the services they require. These include choice in education and training mobility, personal relationships, equipment, ways and means of tackling barriers in order to access health housing employment opportunities across all age groups.

In order to promote independent living among PwDs within the community it is needed to:

- Develop and implement awareness and change of attitudes towards PwDs.

- Develop communication materials and systems within the wider community.

- Develop and implement policies on empowering PwDs on the development of investments, housing, transport and mobility, health, employment, economic well-being, healthy family life.

- Respect and recognize cultural diversity among groups and individuals with PwDs for example utilizing terminologies that are acceptable.

- Empower and encourage participation in decision making (making choices).

\section{BIBLIOGRAPHY}

Beirne-Smith, M., R.F. Ittenbach, \& J.R. Patton. 1998. Mental Retardation (5 ${ }^{\text {th }}$ ed.). New Jersey: Merrill Prentice Hall.

Isaac, M., ed. 2009. Human Rights, Disability and Development in Kenya: A Discourse. Nairobi: Konrad Adenauer Stiftung.

Learner, J. 2006. Learning Disabilities and Related Disorders: Characteristics and Teaching Strategies $\left(10^{\text {th }}\right.$ ed.). Boston: Houghton Mifflin.

Mastropieri, M.A., \& T.E. Scruggs. 2000. The Inclusive Classroom Strategies for Effective Instruction ( $2^{\text {nd }}$ ed.). Ohio, Merrill Prentice Hall.

Meyen, E.L., G.A. Vergason, \& R.J Whelan. 2005. Educating Students with Mild Disabilities: Strategies and Methods ( $2^{\text {nd }}$ ed.). Derives: Lore Publishing Company. 
Mercer, C.D., \& A.R. Mercer. 2001. Teaching Students with Learning Problems ( $6^{\text {th }}$ ed.). Columbus Ohio: Charles E. Merrill.

Quinn, J. 2011. Special Needs Quarterly: Independent Living Skills, http://Blog.abcteach.com/ archives/82.

Ratzka A. 2005. "Independent living." https://www.independentliving.org/.

Republic of Kenya. 2009. The National Special Needs Education Policy Framework. Nairobi: Ministry of Education.

Republic of Kenya. 2007. Kenya Vision: A Globally Competitive and Prosperous Kenya. Nairobi: Kenya. Republic of Kenya. 2005. Sessional paper No. 1 of 2005: A Policy Framework for Education, Training and Research. Nairobi: Government Printers.

Republic of Kenya. 2003. The Persons with Disabilities Act, 2003. Nairobi, Kenya.

Salend, S.T. 1998. Effective Mainstreaming: Creating Inclusive Classroom ( $3^{\text {rd }}$ ed.). New Jersey: Prentice-Hall.

Tailor R. 2000. Assessment of Exceptional Students: Educational and Psychological Procedures (5 ${ }^{\text {th }}$ ed.). Boston: Allyn and Bacon.

\section{INDEX}

\section{Geographical index: Kenya}

\section{AUTHOR}

\section{MARY RUNO}

Dr Mary Runo graduated with a Ph. D in Special Needs Education at Kenyatta University in 2010. She is currently the Chairperson of the Department of Special Needs Education. She specialized in the areas of Learning Disabilities and Intellectual Disabilities. She participated in many workshops and seminars on disabilities locally and internationally. In addition to teaching she is an Assessor of children with disabilities both in and out of school. She is a Mentor to various age groups which she does through Media and visits. 